\title{
A new species of the enigmatic Australian endemic family Trachypetidae (Hymenoptera: Ichneumonoidea): Cercobarcon lasallei sp.n.
}

\section{Andrew D. Austin \& Erinn P. Fagan-Jeffries}

To cite this article: Andrew D. Austin \& Erinn P. Fagan-Jeffries (2020) A new species of the enigmatic Australian endemic family Trachypetidae (Hymenoptera: Ichneumonoidea): Cercobarcon lasallei sp.n., Journal of Natural History, 54:9-12, 553-563, DOI: 10.1080/00222933.2020.1747652

To link to this article: https://doi.org/10.1080/00222933.2020.1747652

冊 Published online: 23 Sep 2020.

Submit your article to this journal $\pi$

山 Article views: 7

Q View related articles ¿

View Crossmark data \lceil 


\title{
A new species of the enigmatic Australian endemic family Trachypetidae (Hymenoptera: Ichneumonoidea): Cercobarcon lasallei sp.n.
}

\author{
Andrew D. Austin (D) and Erinn P. Fagan-Jeffries
}

Australian Centre for Evolutionary Biology and Biodiversity, and Department of Ecology and Evolutionary Biology, School of Biological Science, The University of Adelaide, Adelaide, Australia; South Australian Museum, Adelaide, Australia

\begin{abstract}
The Trachypetidae is a newly recognised family of Ichneumonoidea endemic to Australia and one of the most distinctive wasp groups on the continent based on their large body size and superficial resemblance to some ichneumonids and aculeate wasps. The family is united in the presence of a unique sensory or glandular structure at the base of the mandibles. It is known from three genera: Cercobarcon Tobias, 1979, Megalohelcon Turner, 1918 (= Rhamphobarcon Tobias, 1979) and Trachypetus Guérin de Méneville, 1830, totalling eight described species. Trachypetines are rarely encountered, with very few specimens having been collected or recognised in collections since the group was revised in 1993. Here we report on a newly discovered species from Cape York Peninsula, Queensland, the first to be recognised in more than 25 years, and take much pleasure in naming it after Dr John La Salle, in celebration of his career.

http://www.zoobank.org/urn:Isid:zoobank.org:pub:3F0147A8-F628-4869-B7FD-2E1560145734
\end{abstract}

\section{ARTICLE HISTORY}

Received 8 September 2019

Accepted 20 March 2020

Published online 23

September 2020

Published in print 23

September 2020

\section{KEYWORDS}

Braconidae; Ichneumonidae; Trachypetidae; Cercobarcon; Megalohecon; Trachypetus; John La Salle; Cape York;

Queensland

\section{Introduction}

The Trachypetidae is one of the most distinctive families of Ichneumonoidea, comprising three genera of large-bodied wasps which superficially look like some ichneumonids or aculeates, rather than braconids, where they were previously placed as a subfamily (Quicke et al. 2020). The three genera comprising the family, Cercobarcon Tobias, 1979, Megalohelcon Turner, 1918 (= Rhamphobarcon Tobias, 1979) and Trachypetus Guérin de Méneville, 1830, totalling eight described species, are endemic to the Australian mainland, are mostly restricted to the arid zone and, with one exception, have rarely been collected (Austin et al. 1993; Quicke 2015). Several species are nocturnal and have been taken at light sheets and, apart from this observation, little is known about their biology.

Historically the three genera have been variously treated as members of the braconid subfamily Helconinae, in the case of Megalohelcon, or as separate subfamilies (Cercobarconinae and Trachypetinae). However, Austin et al. (1993) united them into a single subfamily, the Trachypetinae, based on a number of characters, the most important of which is the presence of a unique sensory or glandular structure at the 
base of the mandibles. More recently, Quicke et al. (2020) examined the phylogenetic relationships and taxonomic status of the group employing extensive molecular data and taxon sampling. They confirm the monophyly of the group and robustly place them as sister to the Braconidae. A detailed morphological assessment shows that the three genera lack several synapomorphies that define the Braconidae, and that they possess a number of symplesiomorphies absent from this family but found in some ichneumonids. Based on these findings, and to maintain a realistic diagnosis for the Braconidae, Quicke et al. (2020) raised the Trachypetinae to family rank.

Since a major revision of the group more than 25 years ago (Austin et al. 1993), very few additional specimens have been located, with the exception of Megalohelcon ichneumonoides Tobias, 1979, which is occasionally collected mid-summer at light in central Australia. A recent important find was a series of Trachypetus clavatus Guérin de Méneville (Blue Mts, NSW, 1981) in good condition in the accessions collection at the Australian Museum (Sydney), and a specimen of Cercobarcon in the same collection. The latter specimen turned out to be a new species, the first discovered since Austin et al. (1993), and we take much pleasure in naming this species after Dr John La Salle in celebration of his career. It is also particularly fitting to name this species after John as he was the editor for Systematic Entomology at the time the trachypetine revision was submitted to the journal in late 1992. In typical fashion, John's thoughtful comments on the paper resulted in the published version being much improved. We miss him very much!

\section{Materials and methods}

Terms for general morphology follow Austin et al. (1993), and the standards introduced in the Hymenoptera Anatomy Ontology (HAO) project (Yoder et al. 2010; Seltmann et al. 2012). Terms for sculpture follow Eady (1968). The following abbreviations are used throughout the paper: T1, T2 and T3 for the first, second and third mediotergites, respectively; S1, S2 and S3 for the first, second and third sternites; Qld, Queensland; AMS, Australian Museum, Sydney; ANIC, Australian National Insect Collection, Canberra. Images of body parts and fore wing vein characters were generated using a Visionary Digital BK+ imaging system with a Canon EOS 7D 18 megapixel camera, and Zerene Stacker (Zerene Systems LLC, PMax) software, and cropped and resized in Adobe Photoshop CS6 (Adobe Systems Inc., San Jose, CA, USA).

\section{Taxonomy}

\section{Genus Cercobarcon Tobias 1979}

\section{Type}

Cercobarcon rieki; Tobias, 1979: 75 (by original designation), ANIC (examined).

Cercobarcon: van Achterberg, 1984: 52; Naumann, 1991: 946; Austin et al. 1993:113; Quicke et al. 2020: 7. 


\section{Diagnosis}

Occipital carina well developed; maxillary palps 4-segmented, labial palps 3-segmented; tarsal claws pectinate; fore wing vein 1-SR+M incomplete in basal half, SR1 evenly curved so that marginal cell is acute distally; hind wing vein 1-CU straight; spiracles approximately one-quarter length of propodeal lateral margin or less; in dorsal view metasoma fusiform in shape, terga 2 and 3 not forming a carapace, terga 4-6 visible dorsally.

\section{Comments}

Cercobarcon can be separated from Trachypetus most easily by the latter having a pedunculate metasoma which forms a carapace, and from Megalohelcon by this genus having an incomplete occipital carina, larger propodeal spiracles (0.35 greater than the medial length of the propodeum), simple claws, and fore wing vein CU-1 curved.

The genus is known from five species, including the one described here. It is found broadly across the arid zone from central Queensland to the western margin of the continent, with two species occurring on Cape York Peninsula. The genus is apparently absent from the eastern coastal margin, and temperate/Mediterranean south-east and south-west corners of the continent. However, given that specimens are rarely collected, the distribution of the genus may be broader than is currently documented.

\section{Key to species of Cercobarcon}

1. Lower margin of clypeus evenly curved or at most very slightly indented medially (Figure 1(a))

- Lower margin of clypeus deeply sinuate or bilobed (Figure $1(b, c))$..................................... 4

2. Fore wing vein 1-SR+M with small terminal swelling (Figure 3(b,e)); dorsal head, scutum and scutellum dark brown to black.

- Fore wing vein 1-SR+M without small terminal swelling (Figure 3(c,d)); dorsal head, scutum and scutellum red-brown.

C. rieki Tobias, 1979

3. Posterior marginal carina of propodeum slightly sinuate (Figure 4(b)); metanotum anteromedial area without medial longitudinal carinae, posteromedial area flat (Figure 4(b)); body all black, except propodeum which is brown-black.

C. niger Austin, Wharton and Dangerfield, 1993

- Posterior marginal carina of propodeum evenly curved (Figure 4(a)); metanotum anteromedial area foveate, with several medial longitudinal carinae, posteromedial area slightly depressed (Figure 4(a)); dorsal head, scutum and scutellum dark brown, propodeum red-brown, metasoma dark brown, T1 more red-brown than T2-T6

C. lasallei sp. nov.

4. Clypeus deeply sinuate (Figure 1(b)); postscutellar depression evenly crenulated; propodeum rugose-punctate, with irregular slightly coarser carina....

C. grossi Austin, Wharton and Dangerfield, 1993

Clypeus bilobed (Figure 1(c)); postscutellar depression with strong medial carina and much fainter lateral crenulae; propodeum with strong medial and lateral carinae, background sculpturing varying from almost smooth to rugose-punctate. 

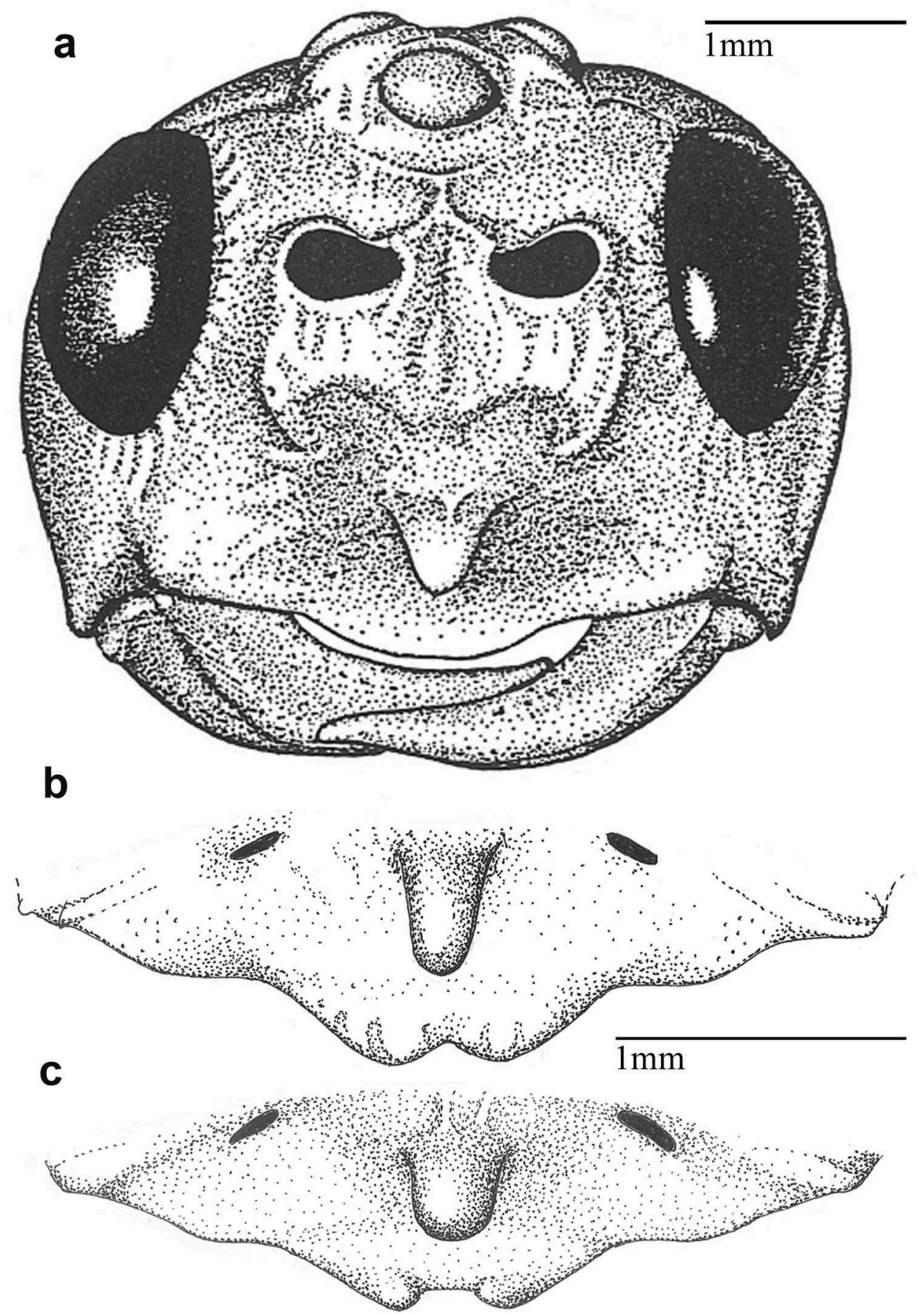

Figure 1. (a) Cercobarcon rieki Tobias, 1979, anterior head showing shape of the clypeus; (b) Cercobarcon grossi Austin, Wharton and Dangerfield, 1993, lower face showing the sinuate shape of the clypeus; (c) Cercobarcon bilobatus Austin, Wharton and Dangerfield, 1993, lower face showing the bilobed shape of the clypeus. 
Cercobarcon Iasallei sp. nov.

(Figures 2, 3(a,b), 4(a,d))

http://www.zoobank.org/urn:Isid:zoobank.org:act:F912578E-6257-4C67-8914C54B11AC9E21

\section{Description (female)}

Body and colour. Length of body $20.0 \mathrm{~mm}$; ratio of antenna to body 1.1; ratio of length of fore wing to body 0.75 ; ratio of length of metasoma to mesosoma 1.3; body dark orange-brown, dorsal head and scutum/scutellum slightly darker than propodeum, base of T1 black; surface densely covered in fine white setae which are slightly longer on propodeum; wings very slightly infuscate; venation darkly pigmented.

Head. Medial horn on lower face broadly pointed, circular in cross section, about as high as basal width; lateral carinae on face broad, lower ends not expanded into blunt teeth; face and frons rugose, lower occiput rugose-punctate; dorsal occiput smooth except for micropunctures associated with pilosity; clypeus with lower margin evenly curved; temples bulging postero-laterally, almost reaching level with longitudinal tangent to eye; occiput broadly excavate; length of temple behind eye about $0.35 \times$ medial length of head; median ocellus about same size as lateral ocellus, lateral ocelli separated by about $0.8 \times$ their diameter, separated from median ocellus by $0.3 \times$ their diameter; in lateral view temple same width as eye; mandible with a single tooth; ventral basal surface of mandible with tuft of long setae; sensory structure on basal outer surface of mandibles identical in shape to that of other described Cercobarcon species; antenna longer than length of body, with approximately 86 flagellomeres.

Mesosoma. Dorsal surface of pronotum transversely wrinkled; mesoscutum slightly wider than long (4.0:3.5), broadly rounded anteriorly, antero-lateral margin slightly emarginate at point of notauli, covered with fine setae; medial and lateral lobes virtually smooth except for micropunctures associated with pilosity, medial lobe convex with illdefined medial longitudinal carina; notauli smooth but very faintly crenulate; scutellar sulcus represented by two deep medial foveae; scutellum with long white pilosity medially, lateral indented areas smooth, without carinae, postscutellar depression divided by indistinct carinae; metanotum anteromedial area foveate, with several medial longitudinal carinae, posteromedial area slightly depressed; lateral metasoma smooth, deeply concave, without carinae; propodeum with medial longitudinal carina and few coarse carinae laterally and posteriorly, carinae enclosing spiracles but not forming a small medial areola; propodeal surface otherwise generally smooth anteromedially and rugose laterally, but sculpturing partly obscured by pilosity; spiracles of moderate size, $0.23 \times$ medial longitudinal length of propodeum (measured from inner margin of surrounding lip of spiracle); posterior marginal carina of propodeum evenly curved; in lateral view pronotum smooth, with pilosity sparser in dorsal part; mesopleuron mostly smooth except for micropunctures associated with pilosity; epicnemial area faintly crenulate; precoxal groove indicated by broad area of rugose-punctate sculpturing; metapleuron mostly smooth with a few coarse crenulae dorsally; coxae and femora with slightly more sparsely placed setae than on tibiae and tarsi; hind tibia widening from base to apex, at 


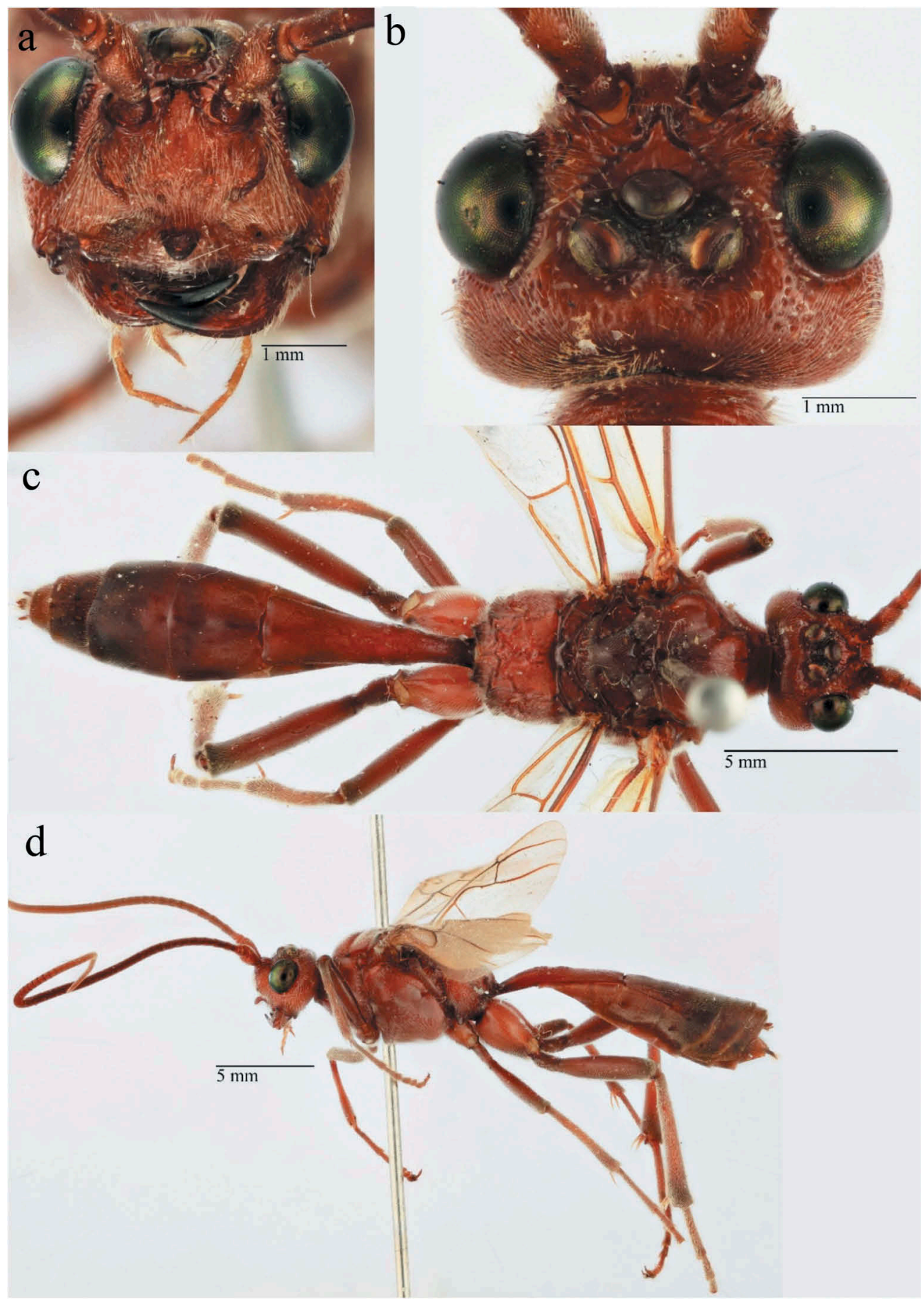

Figure 2. (a) Cercobarcon lasallei sp. nov., + holotype: (a) anterior head; (b) dorsal head; (c) dorsal habitus; (d) lateral habitus. 

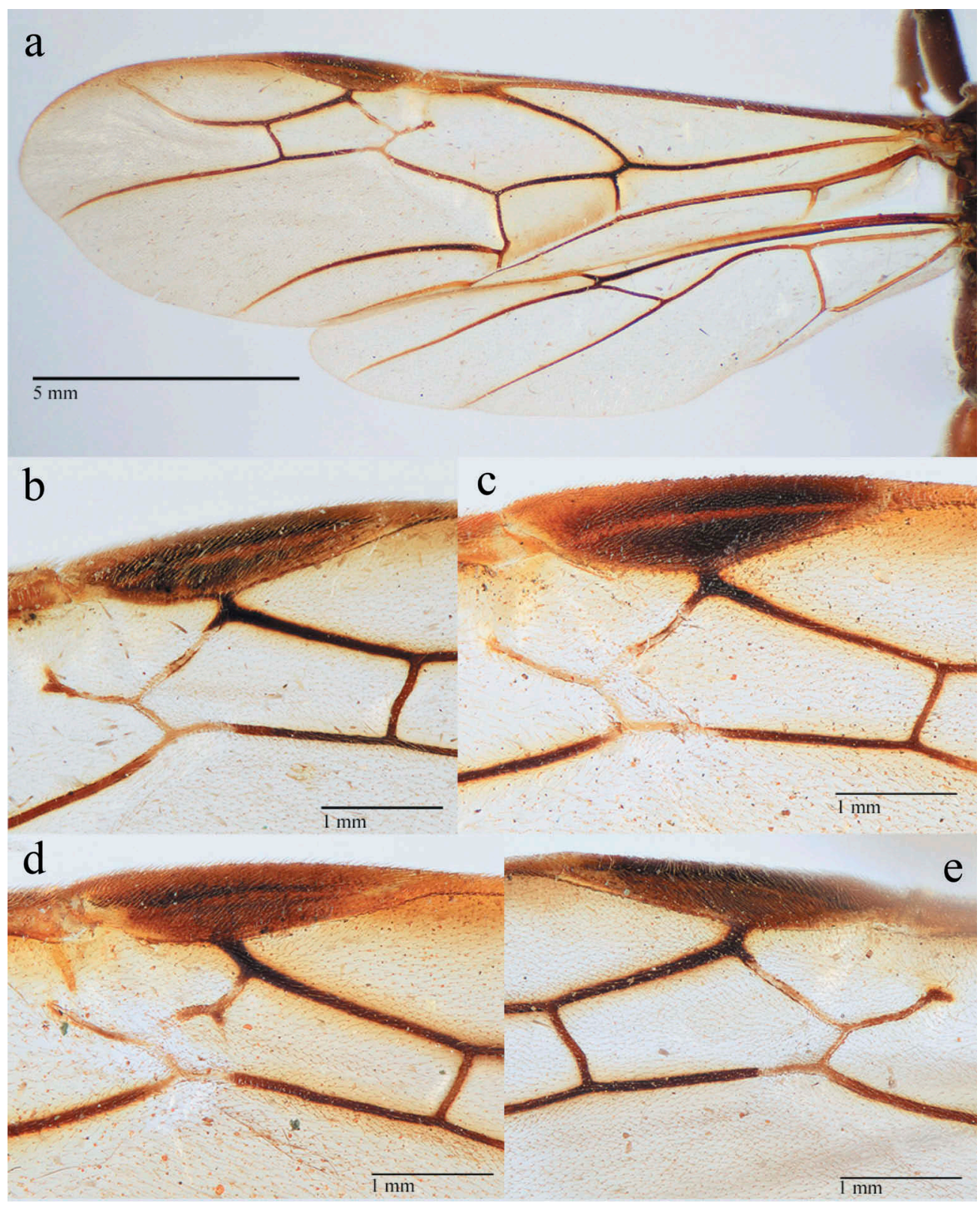

Figure 3. Cercobarcon lasallei sp. nov., $q$ holotype: (a) fore and hind wing; (b) fore wing submarginal cell showing incomplete vein 1-SR+M with small terminal swelling; Cercobarcon rieki Tobias, 1979: (c) o paratype from Western Australia, showing vein 1-SR+M without a terminal swelling; (d) $q$ holotype, showing submarginal cell with incomplete spurious areolet; (e) Cercobarcon niger Austin, Wharton and Dangerfield, 1993: (e) $q$ holotype showing incomplete vein 1-SR+M with small terminal swelling.

apex about as wide as widest part of hind femur; outer hind tibial spur almost equal in length to inner spur, tarsal claws finely pectinate. 


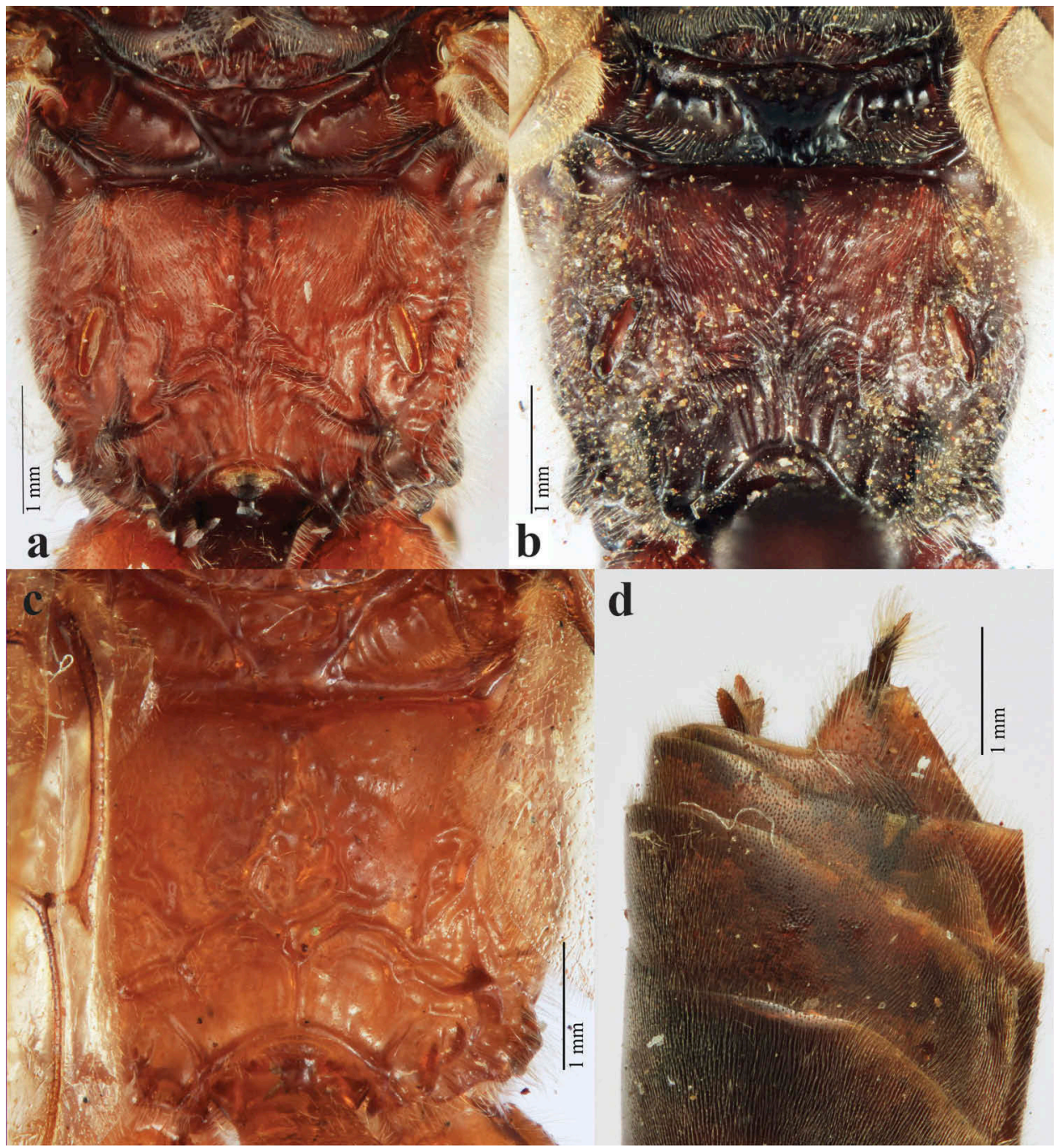

Figure 4. Metanotum and propodeum: (a) Cercobarcon lasallei sp. nov., q holotype; (b) Cercobarcon niger Austin, Wharton and Dangerfield, 1993, o holotype; (c) Cercobarcon rieki Tobias, 1979, $ᄋ$ holotype; (d) Cercobarcon lasallei sp. nov., + holotype, lateral view of posterior metasoma.

Wings. Fore wing without faint spurious vein between 2-SR and 2-M forming an incomplete areolet (as in $M$. rieki holotype); proximal end of 1-SR + M distinctly swollen, 2-M slightly angled at point one-third length from proximal end; hind wing with 10 hamuli.

Metasoma. T1 $2.2 \times$ as long as apical width, slightly longer than T2 $+\mathrm{T} 3$, about $0.4 \times$ length of metasoma, spiracle anterior of midpoint, $0.35 \times$ length of TI from base; border between T2 and T3 clearly indicated by depressed line and by change in density of pilosity; metasomal surface smooth except for micropunctures associated with dense, fine pilosity; pilosity slightly sparser on T1 compared with T2-T6; hypopygium setose throughout, setae shorter than on ovipositor sheaths. 
Male. Unknown.

\section{Diagnosis}

Cercobarcon lasallei can be separated from all other species in the genus on the following combination of characters: lower margin of clypeus evenly curved or at most very slightly indented medially; fore wing vein 1-SR+M with small terminal swelling; posterior marginal carina of propodeum evenly curved; median field of metanotum flat in posterior half, anterior depression without medial longitudinal carina; dorsal head, scutum and scutellum dark brown, propodeum red-brown, metasoma dark brown, T1 more red-brown than T2-T6.

\section{Specimen examined}

Holotype, Australia (Queensland): + , 'Claudie R., near Mount Lamond, Qld, 18 January 1972, D.K. McAlpine, G.A. Holloway' (AMS).

\section{Biology}

Unknown.

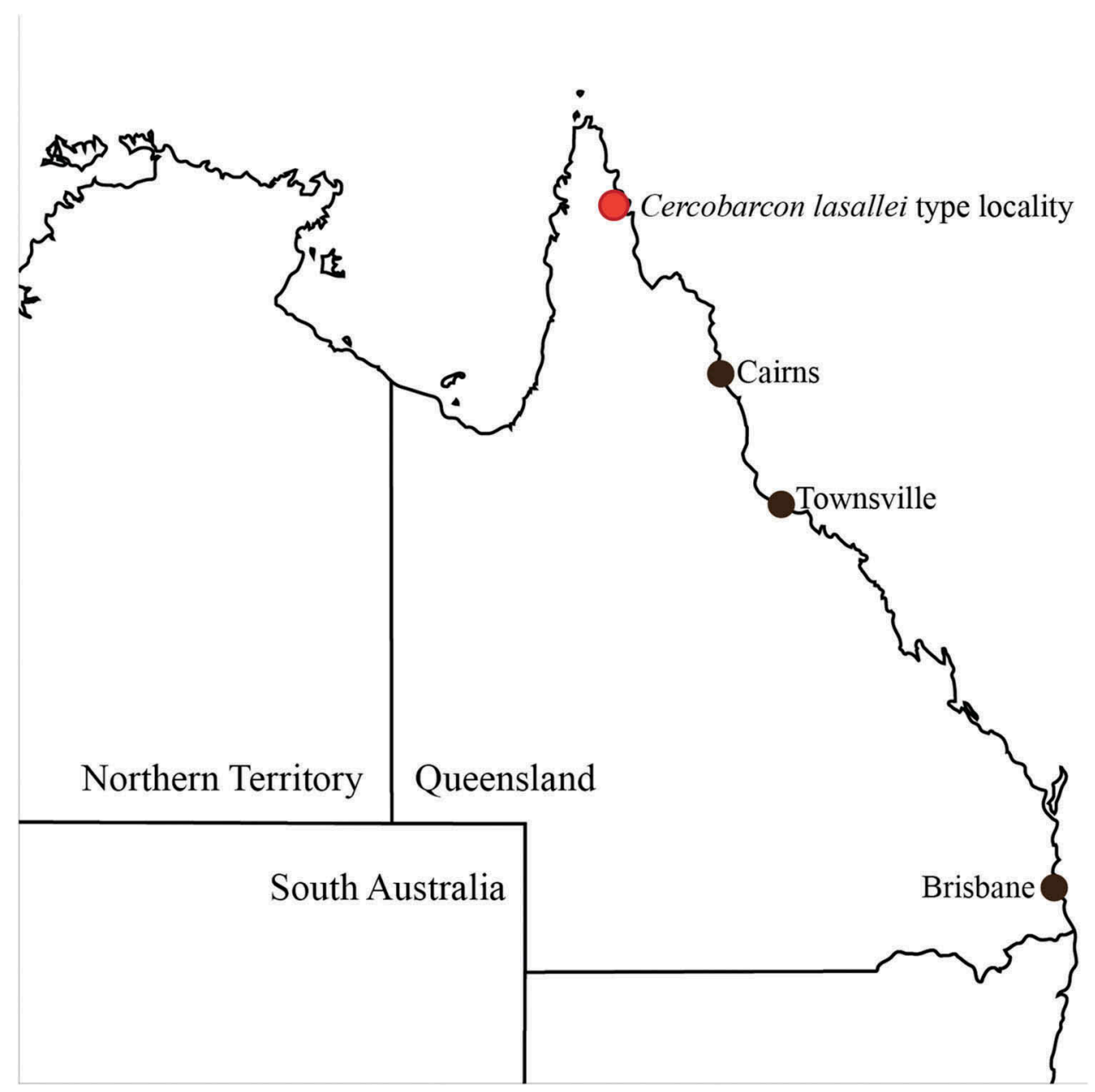

Figure 5. Distribution map showing the collection site of the Cercobarcon lasallei sp. nov. holotype. 


\section{Etymology}

This species is named in honour of our colleague and a close friend of ADA, the late Dr John La Salle.

\section{Distribution}

This species is known only from the type locality (Claudie River) in North Queensland (Figure 5).

\section{Comments}

Normally we would not consider describing a species based on a single specimen, but in this case we feel it is justified based on most members of the Trachypetidae being so rarely collected, and that it is clearly different from the other two species to which it is likely to be most closely related, C. niger and C. rieki (see key to species).

\section{Acknowledgements}

We wish to thank the Australian Biological Resources Study for funding (RF214-16 to ADA) that supported the research that led to this paper.

\section{Disclosure statement}

No potential conflict of interest was reported by the authors.

\section{Funding}

This work was supported by the Australian Biological Resources Study [RF214-16].

\section{ORCID}

Andrew D. Austin (iD http://orcid.org/0000-0002-9602-2276

Erinn P. Fagan-Jeffries (D) http://orcid.org/0000-0002-3322-6255

\section{References}

Austin AD, Wharton RA, Dangerfield PC. 1993. Revision of the endemic Australian subfamily Trachypetinae Schulz s.l. (including Cercobarconinae Tobias) (Hymenoptera: Braconidae). Syst Entomol. 18:97-119. doi:10.1111/j.1365-3113.1993.tb00656.x

Eady RD. 1968. Some illustrations of microsculpture in the Hymenoptera. Proc R Entomol Soc Lond Ser A. 43:66-72.

Guérin de Méneville FE. 1830. Hymenopteres. In: Duperrey LI, editor. Voyage de lu coquille, zoologie. Vol. 2 (2). Paris; p. 197-200.

Quicke DLJ. 2015. The braconid and ichneumonid parasitic wasps: biology, systematics, evolution and ecology. Oxford: Wiley Blackwell; p. 688.

Quicke DLJ, Austin AD, Fagan-Jeffries EP, Hebert PDN, Butcher BA. 2020. Recognition of the Trachypetidae stat. nov. as a new extant family of Ichneumonoidea (Hymenoptera), based on molecular and morphological evidence. Syst Ent. (on-line early):1-12. doi:10.1111/syen.12426 
Seltmann KC, Yoder MJ, Mikó I, Forshage M, Bertone MA, Agosti D, Austin AD, Deans AR. 2012. A hymenopterists' guide to the Hymenoptera Anatomy Ontology: utility, clarification, and future directions. J Hymenopt Res. 27:67-88. doi:10.3897/jhr.27.2961

Tobias VI. 1979. [Two new and one little known subfamilies of Braconidae (Hymenoptera) from Australia.] (in Russian). Entomol Oboz. 58:128-142. [Entomol Rev, 70-79.].

Turner RE. 1918. Notes on the Braconidae in the British Museum. IV. On new Helconinae, mostly Australian. Ann Mag Nat Hist. 9(2):163-173. doi:10.1080/00222931808562359

Yoder M, Mikó I, Seltmann KC, Bertone MA, Deans AR. 2010. A gross anatomy ontology for Hymenoptera. PLoS One. 5:e15991. doi:10.1371/journal.pone.0015991 